\title{
GGE Biplot Analysis of Yield Stability in Multi-environment Trials of Lentil Genotypes under Rainfed Condition
}

\author{
Rahmatollah KARIMIZADEH ${ }^{* *}$, Mohtasham MOHAMMADI ${ }^{1}$, Naser SABAGHNI ${ }^{2}$, Ali \\ Akbar MAHMOODI ${ }^{3}$, Barzo ROUSTAMI ${ }^{3}$, Faramarz SEYYEDI ${ }^{4}$, Fariba AKBARI ${ }^{5}$ \\ ${ }^{1}$ Dryland Agricultural Research Institute, Gachsaran Station P.O. Box. 178, Kohgiloyeh va Boyerahmad \\ Province, Gachsaran,Iran; Karimizadeh_ra@yahoo.com (*corresponding author) \\ ${ }^{2}$ University of Maragheh, Faculty of Agriculture, Department of Agronomy and Plant Breeding, Maragheh, Iran \\ ${ }^{3}$ Dryland Agricultural Research Institute-Shirvan, Sararood and Khorram Abad Stations, Iran \\ ${ }^{4}$ Seed and Plant Improvement Institute-Gonbad Station, Iran \\ ${ }_{5}^{5}$ Jihad-Agriculture Education Center of Sarpol-e-Zahab, Kermanshah, Iran
}

\begin{abstract}
This investigation was done to study GE interaction over twelve environments for seed yield in 18 genetically diverse genotypes. Grain yield performances were evaluated for three years at four locations in Iran using a randomized complete block design. The first two principal components (IPC1 and IPC2) were used to create a two-dimensional GGE biplot that accounted percentages of $49 \%$ and $20 \%$ respectively of sums of squares of the GE interaction. The combined analysis of variance indicated that year and location were the most important sources affecting yield variation and these factors accounted for percentages of $50.0 \%$ and $33.3 \%$ respectively of total $\mathrm{G}+\mathrm{E}+\mathrm{GE}$ variation. The GGE biplot suggested the existence of three lentil mega-environments with wining genotypes G1, G11 and G14. According to the ideal-genotype biplot, genotype G1 was the better genotype demonstrating high mean yield and high stability of performance across test locations. The average tester coordinate view indicated that genotype G1 had the highest average yield, and genotypes G1 and G12 recorded the best stability. The study revealed that a GGE biplot graphically displays interrelationships between test locations as well as genotypes and facilitates visual comparisons.
\end{abstract}

Keywords: GGE biplot, genotype $\times$ environment interaction, multi-environment trials, principal component

\section{Introduction}

Plant breeders perform multi-environment trials (MET) to evaluate new improved genotypes across test environments (several locations and over years), before a specific genotype is released for production to supply growers. In such experiments, genotype $\times$ environment (GE) interaction is a commonly evaluated (Annicchiarico 2002; Kang, 1998; Karimizadeh et al., 2012a; Yan et al., 2007). A GE interaction refers to differential ranking of genotypes across environments and may complicate the selection process and recommendation of a genotype for a target environment (Ebdon and Gauch, 2002; Gauch, 2006). It may also reduce the selection efficiency in different breeding programs because in a GE interaction, measured traits are less predictable and cannot be interpreted using main effects (genotype or environment) and need more analysis (Gauch et al., 2008). GE interaction is also one of the most important reasons for the failure or decreased efficiency of breeding efforts to serve small resource-poor farmers in arid and semi-arid areas (Ceccarelli et al., 1996). Plant breeders perform MET to select favorable genotypes based on both mean yield and performance stability; and to determine whether a test environment is homogeneous or should be divided into various mega-environments (Gauch, 2006; Yan and Kang, 2002).

Different statistical models were used to describe GE interaction and facilitate genotype recommendations in MET. These models have been classified as univariate versus multivariate approaches or parametric versus nonparametric methods (Flores et al., 1998; Karimizadeh et al., 2012b; Lin et al., 1986). Parametric approaches (univariate and multivariate) are based on statistical assumptions considering the distribution of a dataset. Parametric univariate statistics of stability measurements are mostly related to linear regression analysis, variance components or related methods. Alternative strategies are nonparametric stability statistics or analytical clustering procedures that make no specific modeling assumptions about datasets (Lin and Butler, 1990; Huehn, 1996). Several multivariate procedures have been proposed to explore GE interaction including principal component analysis (PCA), additive main effects and multiplicative interactions (AMMI) and genotype plus GE interaction biplot (GGE) analysis (Yan 
et al., 2000; Zoble et al., 1988). The multiplicative GE interaction is far too complex to be summarized by one or two stability parameters using univariate measures of stability. Multivariate statistical approaches explore multidirectional aspects of GE interaction and attempt to extract more information from GE interaction components (Gauch and Zobel, 1996; Gauch et al., 2008; Sabaghnia et al., 2008).

In total phenotypic yield variation, an environment main effect describes more observed variation; while a genotype main effect and GE interaction is usually smaller (Yan, 2002). According to Cooper and Hammer (1996) the relevant variance components in genotype evaluation at MET are genotype main effect $(G)$ and GE interaction, which are regarded as repeatable sources. Therefore Yan $e t$ al. (2000) proposed using both G and GE effects instead of only GE interaction for yield stability analysis. To facilitate use of this model, the biplot approach (Gabriel, 1971) was used to display the GGE of a MET dataset (Yan et al., 2000). Detailed accounts of different models have been presented by Yan and Kang (2002) and Yan et al. (2007). A GGE biplot as a data visualization tool is able to graphically demonstrate a GE interaction pattern. It is an effective tool to identify a mega-environment, genotype evaluation based on the both yield and stability; and evaluation of test environments from a discrimination aspect. A GGE biplot indicating both genotype and environment based on a Site Regression (SREG) model have been used to demonstrate a GE interaction pattern as well as possible (Yan and Tinker, 2005; Yan et al., 2007).

A GGE biplot has been used to study a GE interaction and yield stability analysis of different crops in semiarid and semiarid areas of Iran Dehghani et al. (2006) for barley, Sabaghnia et al. (2008) for lentil, Dehghani et al. (2009) for maize. The objectives of this investigation were: (1) to apply a GGE biplot model to evaluate the magnitude of the effect of GE interaction on grain yield of 18 lentil genotypes tested across five locations, and (2) to evaluate relationships between test environments for identification of favorable genotypes within the identified mega-environment for lentil production areas in semiarid conditions.

\section{Materials and methods}

Seventeen improved lentil genotypes with one cultivar check ('Gachsaran') were used as experimental materials (Tab. 1). The research was performed in a completely randomized block design with four replications across four test location containing Kermanshah, Gorgan, Gachsaran and Shirvan; and during three years from 2003 to 2005 growing period. Sowing was done manually in rows $25 \mathrm{~cm}$ apart. Each plot was $4 \mathrm{~m}^{2}(1 \times 4 \mathrm{~m}$ plots consisting of 4 rows) in size and the harvested plot size was $1.75 \mathrm{~m}^{2}$ (two $3.5 \mathrm{~m}$ rows at the center of each plot). The test locations were selected as samples of lentil growing areas of Iran having variation in latitude, rainfall, soil type, temperature and other agro-climatic factors (Tab. 2).

Primary statistical analyses were performed using the Anderson-Darling normality test and Levene homogeneity test. Homogeneity of residual variance was determined by Bartlett's homogeneity test. To explore G plus GE variability in seed yield of lentil, the SREG model was used presented by the following equation (Yan et al., 2000):

$$
Y_{i j}=\mu+\beta_{j}+\sum_{n=1}^{k} \lambda_{i n} \xi_{i n} \eta_{i n}+\varepsilon_{i j}
$$

where $Y_{i j}$ is the mean of genotype $i$ in environment $j$; $\mu$ is the grand mean; $\beta_{j}$ is the environment $j$ main effect; $n$ is the singular value; $\lambda_{i n}^{j}$ and $\zeta_{\text {in }}$ are, the singular vectors for genotype and environment for $\mathrm{n}=1,2, \ldots$, respectively; and $\varepsilon_{i j}$ is the residual effect. GGE biplots were generated using the first two symmetrically scaled principal components (PC) for an average tester coordinate and polygon view biplots. To visualize correlations between locations, a vector view biplot was made. These graphic analyses were done using the GGEbiplot software (Yan, 2001) and a statistical analysis of variance for the SREG model was done using the SAS codes program as cited by Burgueno et al. (2001).

\section{Results and discussion}

Based on the combined analysis of variance, a significant effect of year (Y) and location (L) was not observed on the grain yield of lentil genotypes in the tests but $\mathrm{Y} \times$

Tab. 1. The yield $\left(\mathrm{kg} \mathrm{ha}^{-1}\right)$ variation of 18 lentil genotypes studied in multi-environmental trials

\begin{tabular}{cccccccc}
\hline Code & Name & Type & Yield & Code & Name & Type & Yield \\
\hline G1 & 'FLIP 96-7L' & Line & 1418.73 & G10 & 'ILL 6030' & Line & 1187.98 \\
G2 & 'FLIP 92-12L' & Line & 1365.64 & G11 & 'Gachsaran' & Cultivar & 1374.14 \\
G3 & 'FLIP 96-13L' & Line & 1287.29 & G12 & 'ILL 7523' & Line & 1334.75 \\
G4 & 'FLIP 96-8L' & Line & 1272.07 & G13 & 'ILL 6468' & Line & 1292.16 \\
G5 & 'FLIP 96-4L' & Line & 1324.46 & G14 & 'ILL 6206 & Line & 1401.88 \\
G6 & 'FLIP 96-14L' & Line & 1096.53 & G15 & 'ILL 62-12' & Line & 1307.35 \\
G7 & 'ILL 5583' & Line & 1304.15 & G16 & 'FLIP 82-1L' & Line & 1272.40 \\
G8 & 'FLIP 96-9L' & Line & 1191.14 & G17 & 'Cabralia' & Line & 1203.28 \\
G9 & 'ILL 6002' & Line & 1329.48 & G18 & 'FLIP 92-15L' & Line & 1314.63 \\
\hline
\end{tabular}


Tab. 2. Geographical properties and mean yield of the 18 lentil genotypes, studied in four locations

\begin{tabular}{|c|c|c|c|c|c|c|c|}
\hline Code & Location & $\begin{array}{c}\text { Position } \\
\text { in Iran }\end{array}$ & $\begin{array}{l}\text { Altitude } \\
\text { (meter) }\end{array}$ & $\begin{array}{c}\text { Longitude } \\
\text { Latitude }\end{array}$ & Soil Texture & $\begin{array}{c}\text { Rainfall } \\
(\mathrm{mm})\end{array}$ & $\begin{array}{c}\text { Yield } \\
\left(\mathrm{kg} \mathrm{ha}^{-1}\right)\end{array}$ \\
\hline 1 & Gorgan & Northeast & 45 & $\begin{array}{l}55^{\circ} 12^{\prime} \mathrm{E} \\
37^{\circ} 16^{\prime} \mathrm{N}\end{array}$ & Silty Clay Loam & 367 & 767 \\
\hline 2 & Kermanshah & West & 1351 & $\begin{array}{l}47^{\circ} 19^{\prime} \mathrm{E} \\
34^{\circ} 20^{\prime} \mathrm{N}\end{array}$ & Clay Loam & 455 & 1923 \\
\hline 4 & Gachsaran & Southeast & 710 & $\begin{array}{l}50^{\circ} 50^{\prime} \mathrm{E} \\
30^{\circ} 20^{\prime} \mathrm{N}\end{array}$ & Silty Clay Loam & 460 & 1747 \\
\hline 5 & Shirvan & Northeast & 1131 & $\begin{array}{l}58^{\circ} 07^{\prime} \mathrm{E} \\
37^{\circ} 19^{\prime} \mathrm{N}\end{array}$ & Loam & 267 & 384 \\
\hline
\end{tabular}

L interaction effect was highly significant, possibly due to changes in environmental conditions, which vary from one environment (year $\times$ location combination) to another (Tab. 3). Genotype demonstrated significant effect, which could be due to changes in genotype characteristics, varying from one genotype to another. The interaction effect of genotype with location $(\mathrm{G} \times \mathrm{L})$ and the three way interaction of factors $(G \times L \times Y)$ were significant, but $G \times Y$ interaction was not significant (Tab. 3). Environment significantly explained about $70 \%(21.06,14.90$ and $34.45 \%$ for year, location and their interactions, respectively) of the total sum of squares due to G + E + GE interaction (Tab. 3 ). However, the partitioning of variance components for environment revealed that both predictable (locations) and unpredictable (year) components were important sources of variation. When GE interaction is due to variation in predictable factors, a plant breeder has the choice of either developing specific genotypes for selected environments or broadly adapted genotypes that can perform well under variable conditions (Dehghani et al., 2006). Anyhow, when GE interaction results from unpredictable sources, a plant breeder needs to develop stable genotypes that can perform reasonably well under a range of environmental conditions.

A remarkable grain yield variation explained by environments (60\%) indicated that environments tested in the study were diverse, with large differences among environmental effects causing the most variation in grain yields of lentil genotypes. The $\mathrm{G} \times \mathrm{L} \times \mathrm{Y}$ or $\mathrm{GE}$ interaction signifi-

Tab. 3. ANOVA analysis of lentil performance trial yield

\begin{tabular}{cccc}
\hline Source of variation & DF & MS $^{\circ}$ & \% of GE \\
\hline Year $(\mathrm{Y})$ & 2 & $8400774^{\mathrm{ns}}$ & 21.06 \\
\hline Location $(\mathrm{L})$ & 3 & $3962077^{\mathrm{ns}}$ & 14.90 \\
$\mathrm{Y} \times \mathrm{L}$ & 6 & $4579496^{\circ}$ & 34.45 \\
$\mathrm{R}(\mathrm{Y} \times \mathrm{L})$ & 36 & 38152 & \\
Genotype $(\mathrm{G})$ & 17 & $320003^{*}$ & 6.82 \\
\hline $\mathrm{G} \times \mathrm{Y}$ & 34 & $80769^{\mathrm{ns}}$ & 3.44 \\
$\mathrm{G} \times \mathrm{L}$ & 51 & $134137^{\circ}$ & 8.58 \\
$\mathrm{G} \times \mathrm{L} \times \mathrm{Y}$ & 102 & $84021^{*}$ & 10.74 \\
\hline Error & 612 & 31713 & 21.06 \\
\hline
\end{tabular}

$\because$ and $^{\text {ns }}$, respectively significant at the 0.01 and 0.5 probability level and non-significant. DF=Degrees of freedom. MS $=$ Mean squares cantly explained $23 \%$ of the $\mathrm{G}+\mathrm{E}+\mathrm{GE}$ variation in grain yield. The relatively large magnitude of the GE interaction sum of squares was about two times larger than that for genotype, indicating that there were sizeable differences in responses according to genotype across environments. Kang and Pham (1991) indicated that GE interactions minimize the usefulness of genotype by confounding yield performance. To better investigate GE interaction, Becker and Leon (1988) showed that assessment of yield stability across many locations and years could increase both repeatability and heritability of studied characters such as grain yield. The significance of GE interaction indicated that differential genotype expression across environments depends on the reaction of genotype on changing environmental conditions across locations and years. Therefore, these results from semiarid conditions of Iran have confirmed that although grain yield has depended on genetic potential, this is modified under environmental factors and their conditions like cold regions of Canada (Yan and Rajcan, 2003).

Results of combined ANOVA for the yearly datasets are shown in Tab. 4, which provides a general picture of the relative magnitudes of effects of genotype, location and the interaction $(G \times L)$ due to $G+L+G L$ variations. Location was the most important source of yield variation (70.85 and $63.79 \%$ of the G + L + GL variation for the first and second year (2003 and 2004, respectively), except in the last year when it accounted for $28 \%$. The relatively large yield variation due to location, which is disjointed to genotype evaluation and mega-environment identification (Gauch and Zobel, 1996), justifies selection of site regression statistical model as the suitable tool for investigation of the multi-environment trials dataset. Regarding the magnitudes of $\mathrm{G} \times \mathrm{L}$ interaction in comparison to genotype main effect, suggests the possible existence of different mega-environments. PC1 and PC2 derived by subjecting the location-centered yield to singular value decomposition (SVD), which make up a genotype plus GL interaction (GGL) biplot, explained from 49\% and 20\% of the total G + GL (Fig. 1).

According to the biplot shown in Fig. 1, the corner genotypes that are the most responsive ones, can be visually determined. These corner genotypes were G1, G6, G9, G10, G11 and G14. In this figure, locations are divided 
Tab. 4. Genotype $(\mathrm{G})$, location $(\mathrm{L})$, and genotype $\times$ location $(\mathrm{GL})$ variance in multi-environment trials

\begin{tabular}{|c|c|c|c|c|c|c|c|}
\hline \multirow{2}{*}{ SOV } & \multirow{2}{*}{$\mathrm{df}$} & \multicolumn{2}{|c|}{2003} & \multicolumn{2}{|c|}{2004} & \multicolumn{2}{|c|}{2005} \\
\hline & & Mean Squares & $\%$ of $\mathrm{L}+\mathrm{G}+\mathrm{GL}$ & Mean Squares & $\%$ of $\mathrm{L}+\mathrm{G}+\mathrm{GL}$ & Mean Squares & $\%$ of $\mathrm{L}+\mathrm{G}+\mathrm{GL}$ \\
\hline Location $(\mathrm{L})$ & 3 & 8694670.96 & 70.85 & $3520783.12^{*}$ & 63.79 & $905614.83^{*}$ & 28.34 \\
\hline Replication / L & 12 & 44458.28 & & 53893.05 & & 16103.70 & \\
\hline Genotype (G) & 17 & $174604.69^{\circ}$ & 8.06 & $177570.51^{*}$ & 18.23 & $129364.71^{*}$ & 22.94 \\
\hline $\mathrm{G} \times \mathrm{L}$ & 51 & $152205.39^{*}$ & 21.09 & $58377.74^{*}$ & 17.98 & $91595.27^{\circ}$ & 48.72 \\
\hline Error & 204 & 42910.01 & & 25026.00 & & 27202.73 & \\
\hline
\end{tabular}

$"$ and ${ }^{\mathrm{ns}}$, respectively significant at the 0.01 and 0.5 probability level and non-significant

into three sectors. The first sector represents Shirvan, with genotype G11 as the most favorable. The second sector represents Gorgan, with genotype G14 as the most favorable. And the other locations (Gachsaran and Kermanshah) made up the third sector; with cultivar G1 as the most favorable. The three other corner genotypes, G6, G9 and G10, were the poorest-yielding (Fig. 1). They were located far away from all of test locations, reflecting the fact that they yielded poorly at each location. Also, those genotypes within the polygon (for example G2 and G13 for Gorgan) were less responsive to location than the corner genotypes. If mega-environments are identified by different winning genotypes (Gauch and Zobel, 1996), Fig. 1 indicates the existence of three mega-environments for lentil in Iran, namely the G1-winning niche (warm climatic regions), G11-winning niche (cold climatic region), and the G14winning niche (moderate climatic region). However, this subdivision pattern can only be considered as a suggestion insofar as it is based solely on one MET dataset. GGL biplots for individual years were similarly constructed and indicated for each year that some of the test locations fell into different sectors and some test locations fell into similar sectors but the general pattern of location groupings did not vary across years (results are not presented). In most cases, determined mega-environments corresponded with the traditional areas for lentil production Iran.

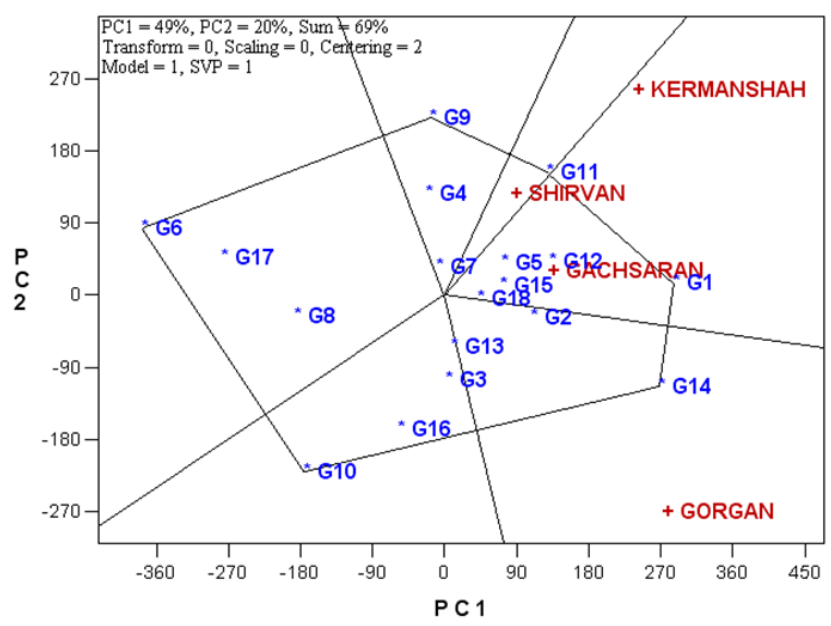

Fig. 1. GGE biplot identification of winning genotypes and their related mega-environments
Based on Fig. 2, it is possible to assess both mean yield and stability performance through a biplot. An average tester coordinate (ATC) horizontal axis passes through the biplot origin and the average location and the oval show the positive end of the ATC horizontal axis. The average yields of genotypes are estimated by projections of their markers on to the ATC horizontal axis. Thus, genotype G1 had the highest average yield, and G6 had the lowest (Fig. 2). Stability of each genotype is explored by its projection onto the ATC vertical axis. The smaller the absolute length of projection of a genotype, the more stable it is. Thus, genotypes $\mathrm{G} 9$ and $\mathrm{G} 10$ were the least stable and genotypes $\mathrm{G} 1$, G2, G5, G7, G8, G12, G15 and G18 were the most stable. However, considering both mean yield and stability performance, genotypes G1 following to G12, G2, G15, G5, G18 and G7 could be regarded as the most favorable. Yield performances consist of mean yield and stability concepts. Plant breeders explore genotypes that indicate yield stability well as high yield across environments (Kang, 2002). Estimates for stability have derived from an analysis of GE interaction (Hill et al., 1998) and the significant GE interaction have resulted from changes in the magnitude of differences between genotypes in different environments. If no GE interaction exists, the mean difference among the studied genotypes summoned by the observed phenotypes in different environments is constant.

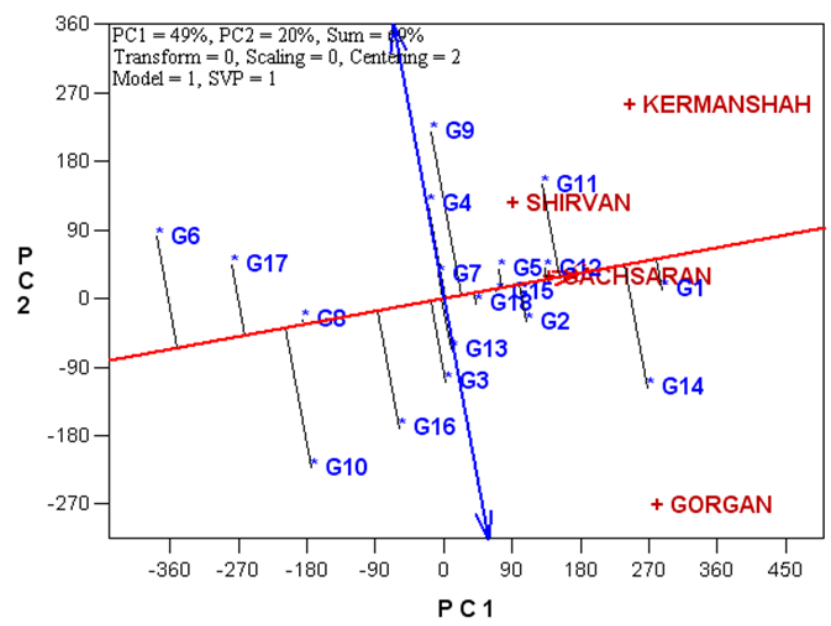

Fig. 2. GGE biplot of mean and stability of 18 lentil genotypes for yield and specific genotype $\times$ environment interactions 


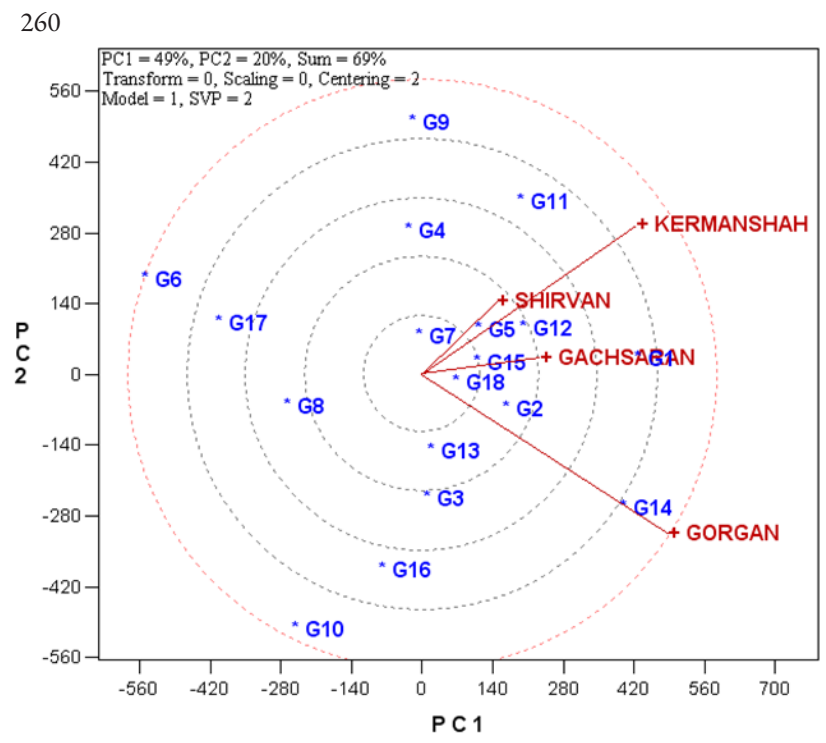

Fig. 3. Vector view of GGE biplot for relationships among locations

Fig. 3 provides a summary of interrelationships between test locations. The location vectors are lines that connect the biplot origin and the markers of test locations and the angle between them is related to the correlation coefficient. In other words, the cosine of the angle approximates the correlation coefficient between related locations (Kroonenberg, 1995). According to the angles of test location vectors, the four locations are grouped into two major groups. One group includes Shirvan, Gachsaran and Kermanshah while the other group involves Gorgan. This result is relatively coincident with the geographic pattern belonging to different location types, (warm or cold versus moderate climatic conditions respectively). Similarly this tool was used for evaluation of interrelationships between 18 lentil genotypes (Fig. 4). The overall picture of interrelationships between genotypes indicated that there were different genotype groups. In other words, these studied genotypes had diverse characteristics in terms of perfor-

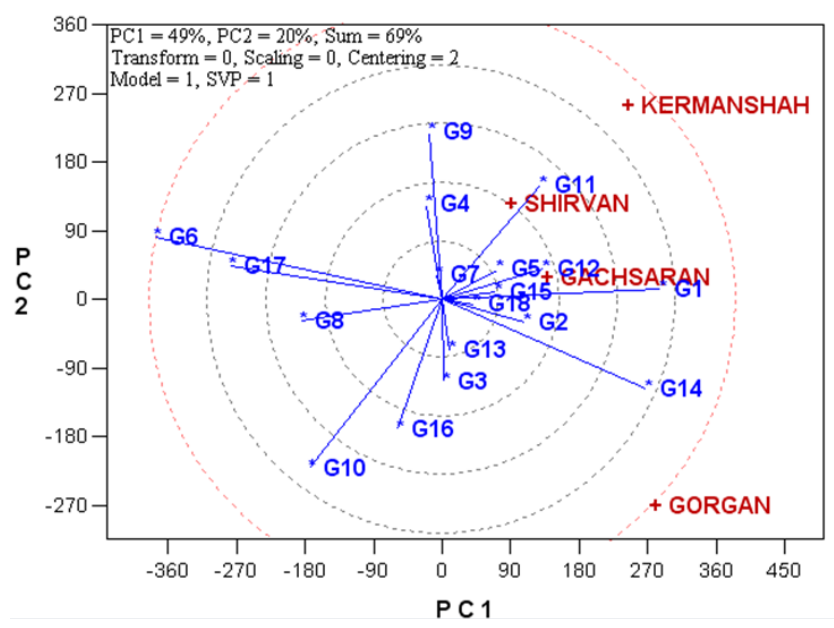

Fig. 4. Vector view of GGE biplot for relationships among genotypes mance for grain yield and stability. This could be related to different geographical sources of the parent plants (Tab. 2). It is interesting that none of the genotypes had strong positive associations with the most favorable genotype (G1). Only genotype G14 had a relatively significant moderate correlation with G1. However, most of the above results on location or genotype can be verified from original data but some of them are not consistent with original data. These discrepancies are predicted because the GGL biplot explained only $69 \%$ rather than $100 \%$ of the total variation due to $\mathrm{G}+\mathrm{L}+\mathrm{GL}$ sources. Therefore all data contain some error, but according to Yan and Hunt (2002) and Yan and Tinker (2005) as the biplot shows and makes conclusions on the overall pattern of the whole dataset; these predictions are probably more reliable than individual observations.

In Fig. 5, the center of the concentric circles is where an ideal genotype (high mean yield and the most stable one) should be located. In other words, projection of the ideal genotype on the ATC horizontal axis is equal to the longest vector of all genotypes and its projection on the ATC vertical axis is obviously zero (it is absolutely stable). Therefore, a smaller the distance from genotype to the virtual ideal genotype represents an ideal genotype. Therefore, genotype G1 following to genotypes G11, G12 and G14 were closest to the concentric center, but genotype G6 was the closest to this position (Fig. 5). Also, genotypes G2, G5, G15 and G18 do not seem to be meaningfully different from other genotypes such as G8, G10, G16 and G17 that were apparently inferior. Similar to the ideal genotype, it is possible to define ideal location or environment for ranking of test locations according to their discriminating ability and suitability of representation. Centers of the concentric circles in Fig. 6 are where an ideal location should be. The projection of ideal location on the ATC horizontal axis is equal to the longest vector of all locations (the most discriminating location) and its projection on the ATC vertical axis was zero, meaning that it

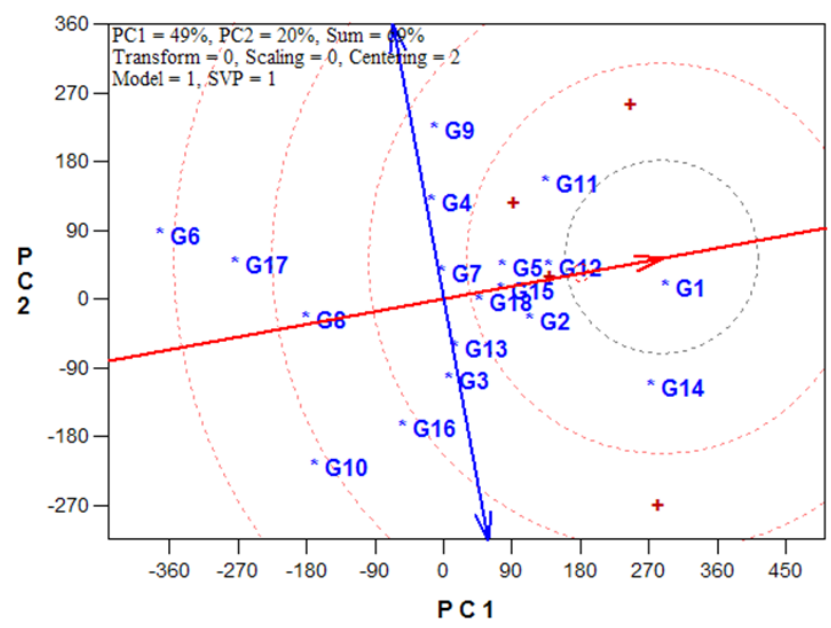

Fig. 5. GGE biplot of ideal genotype and comparison of the genotypes with the ideal genotype 


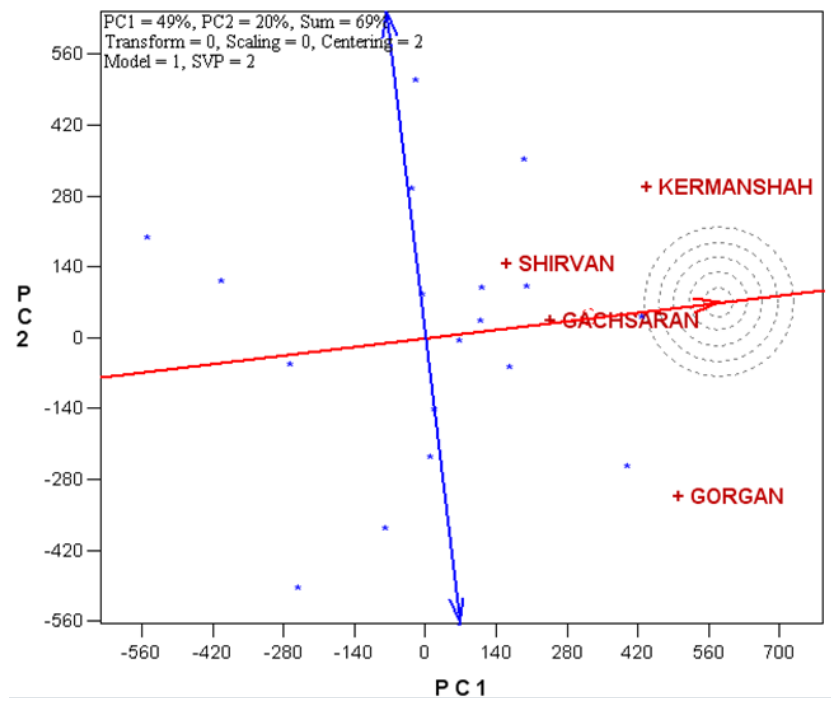

Fig. 6. GGE biplot of ideal location and comparison of the location with the ideal location

is absolutely representative of average location. Thus, the closer a location is to this virtual ideal location, the better it is as a test location. Therefore, Shirvan, Kermanshah and Gachsaran were the best environments and do not seem to be meaningfully different from each other (Fig. 6). Also the discriminating ability and suitability of representation of the Gorgan location was low. However, it seems that the selected test locations were different from each other and future multi-environment trials must be performed on all of them because they vary in most geographical properties such as latitude, rainfall, soil type, temperature and other agro-climatic factors (Tab. 2).

Compared to the conventional procedures of yield stability analysis, the GGE biplot analysis integrates some features from all of them such as a visual interpretation of the GE interaction. The which-won-where or identification of mega-environments as well as their wining genotypes are important aspects of a biplot analysis. A biplot analysis could be performed either by the GGE model or the AMMI method, but the AMMI method could be misleading for identification of the 'which-won-where' problem because it removes genotype as a main effect. The GGE biplot is more interpretative and facilitates pair-wise genotype comparisons. Also, the GGE biplot has many visual interpretations in comparison to AMMI that particularly allows visualization of any crossover in the GE interaction (Ding et al., 2007). A GGE biplot may fail to describe most observed variation and thus fails to show all patterns. In these cases, it can be ensured that the first two PCs of a biplot still display the most important linear patterns of data (Yan and Hunt, 2002). In addition, comparing different AMMI models, the GGE biplot is close to the best AMMI model in most investigations (Ma, 2004) and is more useful in practice than AMMI in terms of description of PC1 score (Yan et al., 2000). Finally it could be concluded that the GGE biplot model and its software are excellent tools for visual MET data analysis in plant breeding programs.

\section{Conclusions}

Three distant mega-environments were identified for lentil producing areas of Iran including Shriven with G11 as the most favorable, Gorgan with G14 as the most favorable and Gachsaran and Kermanshah with G1 as the most favorable. Genotype G1 demonstrated a high mean yield as well as stability presenting a suitably good plant material for future breeding programs. Furthermore the GGE biplot procedure was an effective tool for visual interpretation of the complex GE interaction and yield stability for studies applied to plant breeding programs.

\section{Acknowledgments}

We wish to thank Dr. Wei-Kai Yan (Eastern Cereal Oilseed Research Center of Agriculture and Agri-Food Canada) for making available a time-limited version of GGEbiplot as "testBiplotxlsx". Contributions of the cooperators of the Iran's Dryland Agricultural Research Institute research stations are also gratefully acknowledged.

\section{References}

Annicchiarico P (2002). Defining adaptation strategies and yield stability targets in breeding programmes, 365-383 $\mathrm{p}$. In: Kang MS (Ed.). Quantitative genetics, genomics, and plant breeding, Wallingford, UK, CABI.

Becker HC, Leon J (1988). Stability analysis in plant breeding. Plant Breed 101:1-23.

Burgueno J, Crossa J, Vargas M (2001). SAS programs for graphing GE and GGE biplots. Biometrics and Statistics Unit, CIMMYT.

Ceccarelli S (1996). Adaptation to low or high input cultivation. Euphytica 92:203-214.

Cooper M, Hammer GL (1996). Plant adaptation and crop improvement. CAB International, International, Rice Research Institute, and the International Crops Research Institute for the Semi-Arid Tropics, Wallingford, UK.

Dehghani H, Ebadi A, Yousefi A (2006). Biplot analysis of genotype by environment interaction for barley yield in Iran. Agron J 98:388-393.

Dehghani H, Sabaghnia N, Moghaddam M (2009). Interpretation of genotype-by-environment interaction for late maize hybrids' grain yield using a biplot method. Turk J Agric Fores 33:139-148.

Ding M, Tier B, Yan W (2007). Application of GGE biplot analysis to evaluate Genotype $(G)$, Environment $(E)$ and $G$ $\times$ E interaction on P. radiata: a case study. Paper presented to Australasian Forest Genetics Conference Breeding for Wood Quality, 1114 April 2007, Hobart, Tasmania, Australia.

Ebdon JS, Gauch HG (2002). Additive main effect and mul- 
262

tiplicative interaction analysis of national turfgrass performance trials: I. Interpretation of genotype $\times$ environment interaction. Crop Sci 42:489-496.

Flores F, Moreno MT, Cubero JI (1998). A comparison of univariate and multivariate methods to analyze environments. Field Crops Res 56:271-286.

Gabriel KR (1971). The biplot graphic display of matrices with application to principal component analysis. Biometrika 58:453-467.

Gauch HG (2006). Statistical analysis of yield trials by AMMI and GGE. Crop Sci 46:1488-1500.

Gauch HG, Piepho HP, Annicchiarico P (2008). Statistical analysis of yield trials by AMMI and GGE: Further considerations. Crop Sci 48:866-889.

Gauch HG, Zobel RW (1996). Optimal replication in selection experiments. Crop Sci 36:838-843.

Hill J, Becker HC, Tigerstedt PMA (1998). Quantitative and Ecological Aspects of Plant Breeding. Chapman \& Hall, London, $155-211 \mathrm{p}$.

Huehn M (1996). Non-parametric analysis of genotype $\times$ environment interactions by ranks, 213-228 p. In: Kang MS, Gauch HG (Eds.). Genotype by environment interaction. CRC Press, Boca Raton, FL.

Kang MS, Pham HN (1991). Simultaneous selection for high yielding and stable crop genotypes. Agron J 83:161-165.

Kang MS (2002). Quantitative genetics, genomics, and plant breeding. Wallingford, UK, CABI.

Kang MS (1998). Using genotype-by-environment interaction for crop cultivar development. Adv Agron 62:199-252.

Karimizadeh R, Mohammadi M, Sabaghnia N, Shefazadeh MK (2012a). Using Huehn's Nonparametric Stability Statistics to Investigate Genotype $\times$ Environment Interaction. Not Bot Horti Agrobo 40:195-200.

Karimizadeh R, Mohammadi M, Sabaghnia N, Shefazadeh MK, Pouralhossini J (2012b). Univariate stability analysis methods for determining genotype $\times$ environment interaction of durum wheat grain yield. African J Biotech 11:2563-2573.
Kroonenberg PM (1995). Introduction to biplots for $G \times E$ Tables. Dep. of Mathematics, Res. Rep. 51. Univ. of Queensland, Australia.

Lin CS, Binns MR, Lefkovitch LP (1986). Stability analysis: where do we stand? Crop Sci 26:894-900.

Lin CS, Butler G (1990). Cluster analyses for analyzing twoway classification data. Agron J 82:344-348.

Sabaghnia N, Dehghani H, Sabaghpour SH (2008). Graphic analysis of genotype $\times$ environment interaction of lentil yield in Iran. Agron J 100:760-764.

Yan W (2001). GGEbiplot- a Windows application for graphical analysis of multi-environment trial data and other types of two-way data. Agron J 93:1111-1118.

Yan W, Hunt LA, Sheng Q, Szlavnics Z (2000). Cultivar evaluation and mega-environment investigation based on GGE biplot. Crop Sci 40:596-605

Yan W, Kang MS, Ma B, Woods S, Cornelius PL (2007). GGE biplot vs. AMMI analysis of genotype-by-environment data. Crop Sci 47:643-655.

Yan W (2002). Singular value partitioning in biplot analysis of multievironment trial data. Agron J 94:990-996.

Yan W, Hunt LA (2002). Biplot analysis of diallel data. Crop Sci 42:21-30.

Yan W, Kang MS (2002). GGE biplot analysis: A graphical tool for breeders, geneticists, and agronomists. CRC Press, Boca Raton, FL.

Yan W, Rajcan I (2003). Prediction of cultivar performance based on single-versus multiple-year test in soybean. Crop Sci 43:549-555.

Yan W, Tinker NA (2005). An integrated system of biplot analysis for displaying, interpreting, and exploring genotype byenvironment interactions. Crop Sci 45:1004-1016.

Zoble RW, Wright MJ, Gauch HG (1988). Statistical analysis of a yield trial. Agron J 80:388-393. 